\begin{tabular}{|c|l|}
\hline Title & $\begin{array}{l}\text { A ssessing the roles of presynaptic ryanodine receptors and adenosine receptors in caffeine induced enhancement of } \\
\text { hippocampal mossy fiber transmission }\end{array}$ \\
\hline Author(s) & Sato, Ikuma; Kamiya, Haruy uki \\
\hline Citation & $\begin{array}{l}\text { Neuroscience Research, 71(2), 183-187 } \\
\text { https://doi.org/10.1016/.neures.2011.07.001 }\end{array}$ \\
\hline Issue Date & 2011-10 \\
\hline Doc URL & http:/hdl.handle.net/2115/47363 \\
\hline Type & article (author version) \\
\hline File Information & NR71-2_183-187.pdf \\
\hline
\end{tabular}

Instructions for use 


\title{
Assessing the roles of presynaptic ryanodine receptors and adenosine receptors in caffeine-induced enhancement of hippocampal mossy fiber transmission
}

\author{
Ikuma Sato and Haruyuki Kamiya \\ Department of Neurobiology, Hokkaido University School of Medicine, \\ Kita 15 Nishi 7, Kita-ku, Sapporo, 060-8638, Japan
}

Correspondence to: Ikuma Sato

Department of Neurobiology, Hokkaido University School of Medicine, Sapporo, 060-8638, Japan

TEL, +81-11-706-5028; FAX, +81-11-706-7863

E-mail address, ikuma_sato@ec.hokudai.ac.jp 


\begin{abstract}
Caffeine robustly enhances transmitter release from the hippocampal mossy fiber terminals, although it remains uncertain whether calcium mobilization through presynaptic ryanodine receptors mediates this enhancement. In this study, we adopted a selective adenosine A1 blocker to assess relative contribution of A1 receptors and ryanodine receptors in caffeine-induced synaptic enhancement. Application of caffeine further enhanced transmission at the hippocampal mossy fiber synapse even after full blockade of adenosine A1 receptors. This result suggests that caffeine enhances mossy fiber synaptic transmission by two distinct presynaptic mechanisms, i.e. removal of A1 receptor-mediated tonic inhibition and ryanodine receptor-mediated calcium release from intracellular stores.
\end{abstract}

Key words: hippocampus; mossy fiber; caffeine; ryanodine receptor; presynapse; $\mathrm{Ca}^{2+}$ store 
Calcium ions $\left(\mathrm{Ca}^{2+}\right)$ play important roles in neurotransmitter release from presynaptic terminals and its modulation by neuronal activity. In addition to $\mathrm{Ca}^{2+}$ influx from extracellular fluid, $\mathrm{Ca}^{2+}$-induced $\mathrm{Ca}^{2+}$ release (CICR) from intracellular stores regulate presynaptic intracellular $\mathrm{Ca}^{2+}$ concentration in some types of synapses. The roles of presynaptic $\mathrm{Ca}^{2+}$ store in regulating transmitter release have been suggested for a long time (Onodera, 1973; Erulkar and Rahamimoff, 1978). Recently, much evidence has been accumulated for the presence of ryanodine-sensitive store in presynaptic terminals and/or axons at the hippocampal mossy fiber synapse onto CA3 pyramidal cell (Liang et al., 2002; Lauri et al., 2003; Sharma et al., 2003). This notion was also supported by the finding that application of caffeine, drug acting on ryanodine receptor channels to release $\mathrm{Ca}^{2+}$ from intracellular stores, strongly enhanced synaptic transmission at the hippocampal mossy fiber synapse (Shimizu et al., 2008). This result also suggests the presence of functional ryanodine receptors and possible CICR mechanisms may be involved in robust activity-dependent presynaptic plasticity characteristic for this synapse.

However, caffeine is also known to block adenosine A1 receptors potently (Fredholm et al., 1999). It was found that extracellular adenosine acts on presynaptic A1 receptors and suppresses transmitter release via activation of $\mathrm{G}_{\mathrm{i} / \mathrm{o}}$ (Dunwiddie and Hoffer, 1980). Previous studies demonstrated that application of the selective A1 receptor antagonist induced potent enhancement of mossy fiber response in vitro (Moore et al., 2003) and also in vivo (Klausnitzer and Manahan-Vaughan, 2008; Hagena and Manahan-Vaughan, 2010) by reducing tonic inhibitory effects of ambient adenosine. This effect is prominent at the mossy fiber synapse in comparison with adjacent associational-commissural synapse, and contributes, at least partly, to its characteristics such as low-release probability, large frequency facilitation and paired-pulse facilitation 
(Nicoll and Schmitz, 2005).

Therefore, it remains to be determined whether activation of ryanodine receptors, in addition to blocking A1 receptors, mediates the caffeine-induced enhancement at this synapse. In this study, we addressed this issue using a selective blocker of A1 receptor (8-cyclopentyl-1,3-dipropylxanthine; DPCPX) and an inhibitor of ryanodine receptor channels (ryanodine). We found that caffeine enhanced the hippocampal mossy fiber response even under full blockade of A1 receptors, and that the magnitude of enhancement was decreased in the presence of ryanodine. We also measured presynaptic $\mathrm{Ca}^{2+}$ levels within mossy fiber terminals by fluorescence recording during application of DPCPX and caffeine. A part of this work was presented elsewhere in an abstract form (Sato and Kamiya, 2009).

All experiments were performed according to the guidelines for the care and use of laboratory animals of Hokkaido University. Recordings of field excitatory postsynaptic potentials (fEPSPs) elicited by mossy fiber stimulation were made as described before (Kamiya et al., 1996). Briefly, transverse hippocampal slices (400 $\mu \mathrm{m}$ thick) were prepared from C57BL/6J mice (12-28 days old) in an ice-cold sucrose solution containing (in mM) $40 \mathrm{NaCl}, 2.5 \mathrm{NaHCO}_{3}, 10$ glucose, 150 sucrose, $4 \mathrm{KCl}, 1.25$ $\mathrm{NaH}_{2} \mathrm{PO}_{4}, 0.5 \mathrm{CaCl}_{2}$, and $7 \mathrm{MgCl}_{2}$ (Geiger et al., 2002). Slices were continuously superfused with a solution (artificial cerebrospinal fluid; ACSF) containing (in mM) $127 \mathrm{NaCl}, 1.5 \mathrm{KCl}, 1.2 \mathrm{KH}_{2} \mathrm{PO}_{4}, 26 \mathrm{NaHCO}_{3}, 10$ glucose, $4 \mathrm{CaCl}_{2}$, and $4 \mathrm{MgCl}_{2}$, which was saturated with $95 \% \mathrm{O}_{2}$ and $5 \% \mathrm{CO}_{2}$.

Mossy fibers were stimulated at the granule cell layer of dentate gyrus through a concentric bipolar electrode of $100 \mu \mathrm{m}$ tip diameter, and the evoked fEPSPs were recorded in the stratum lucidum of the CA3 region through a glass microelectrode of about $10 \mu \mathrm{m}$ tip diameter filled with ACSF. Group II metabotropic glutamate receptor 
agonist (2S,2'R,3'R)-2-(2',3'-dicarboxycyclopropyl)glycine (DCG-IV, $1 \mu \mathrm{M})$ (Tocris Bioscience, Bristol, UK) was applied at the end of each experiment to verify the mossy fiber origin of the fEPSPs.

In this study, we paid much attention to reduce accumulation of DPCPX (Tocris Bioscience, Bristol, UK) in the perfusing system. Several previous studies have pointed out that DPCPX is readily accumulated in the perfusing system due to its poor water solubility (McPherson et al., 2010) and thereafter released into perfusing solution gradually. This unusual property of DPCPX will result in underestimation of action of adenosine A1 receptors. Therefore we washed the system thoroughly with $70 \%$ ethanol at least for 20 minutes before and after each experiment.

Fluorescence recordings of presynaptic $\mathrm{Ca}^{2+}$ at mossy fiber terminals were made as described before (Kamiya and Ozawa, 1999). In brief, membrane permeable $\mathrm{Ca}^{2+}$ indicator Oregon Green 488 BAPTA-1 AM (OGB1, $0.1 \mathrm{mM}$ in DMSO with 1\% pluronic acid) (Invitrogen, Carsbad, CA) was locally injected into stratum lucidum and loaded into mossy fiber terminals via axons. We attempted to detect minimal changes of basal fluorescence levels by using high-affinity $\mathrm{Ca}^{2+}$ indicator OGB1. The fluorescence was measured every 5 min with a single photodiode. The fEPSPs were also recorded simultaneously as described above.

All data are expressed as mean \pm SEM. For statistical analysis, we adopted peak values of fEPSPs after application of each drug, and they were presented in percentile form. Statistical analysis was performed using Student's $t$-test, and $P$ values less than 0.05 were accepted for statistical significance.

First, we tested the effect of caffeine on synaptic transmission at the hippocampal mossy fiber synapses. Application of $10 \mathrm{mM}$ caffeine (Wako, Osaka, Japan) for $20 \mathrm{~min}$ caused strong enhancement of the first fEPSPs (to $404 \pm 51 \%$ of control, $n=4$; Fig. 1). 
Although the second fEPSPs evoked by paired stimuli at $50 \mathrm{~ms}$ interval was also enhanced (to $222 \pm 32 \%$ of control, $n=4$; Fig. 1), the magnitude was smaller than the first fEPSPs $(P=0.019)$. In addition, paired-pulse facilitation decreased after application of caffeine (from $262 \pm 16 \%$ to $141 \pm 10 \%, \mathrm{n}=4, P=0.00074$ ). These results suggest that caffeine acts on some presynaptic components to enhance release probability. However, we can't rule out the possibility that the effect of caffeine is solely due to the action on presynaptic adenosine A1 receptors to remove tonic inhibition of mossy fiber transmission by ambient adenosine in extracellular space (Moore et al., 2003), since application of a selective blocker of adenosine A1 receptors, another prominent target of caffeine, has been shown to enhance mossy fiber transmission presynaptically. Then we aimed to examine whether this caffeine-induced enhancement is mediated by activation of ryanodine receptors in addition to by blocking A1 receptors. For this purpose, we used the selective adenosine A1 receptor antagonist DPCPX, which reportedly blocks A1 receptors with high affinity $\left(\mathrm{K}_{\mathrm{d}}=0.45 \mathrm{nM}\right.$; Lohse et al., 1987). At first, we examined the saturating concentration at which DPCPX blocks A1 receptors completely. Application of $1 \mu \mathrm{M}$ DPCPX for 20 min enhanced fEPSPs (to $209 \pm 38 \%$ of control, $\mathrm{n}=5$; Fig. $2 \mathrm{~A}$ and $\mathrm{B}$ ), but subsequent application of $2 \mu \mathrm{M}$ DPCPX didn't cause further enhancement (to $186 \pm 31 \%$ of control, $P=0.65$; Fig. 2A and B). In addition, application of $1 \mu \mathrm{M}$ DPCPX reversed and further enhanced the fEPSPs (to $242 \pm 55 \%$ of control, $n=4$; Fig. $2 \mathrm{C}$ and D) that had already reduced by the specific A1 receptors agonist N-cyclopentyladenosine (CPA) (800 nM, Sigma-Aldrich) (to $24 \pm 3 \%$ of control). Enhancement of DPCPX $(1 \mu \mathrm{M})$ alone (to $239 \pm 32 \%$ of control, $\mathrm{n}=13$, not shown) is almost identical with that with prior application of CPA (to $242 \pm 55 \%$ of control, $P=0.83$ ). These results demonstrate that DPCPX at $1 \mu \mathrm{M}$ blocks A1 receptors almost completely. 
Next we assessed the effect of caffeine on A1 receptors. Application of $1 \mu \mathrm{M}$ DPCPX for $20 \mathrm{~min}$ after $10 \mathrm{mM}$ caffeine treatment caused only a little enhancement (to $112 \pm$ $3 \%, n=7$; Fig. $3 \mathrm{~A}$ and B). In another series of experiments, application of DPCPX (1 $\mu \mathrm{M}$ ) for 20 min enhanced fEPSPs (to $171 \pm 18 \%$ of control) and subsequent application of $10 \mathrm{mM}$ caffeine for $20 \mathrm{~min}$ after $1 \mu \mathrm{M}$ DPCPX further enhanced fEPSPs (to $414 \pm$ $30 \%$ of control, $\mathrm{n}=11$; Fig. $3 \mathrm{C}$ and $\mathrm{D})$. In these experiments, the magnitude of enhancement by DPCPX with or without preceding caffeine treatment was significantly different $(P=0.017)$. This suggests that $10 \mathrm{mM}$ caffeine effectively blocked A1 receptors. Furthermore, in the latter experiment, application of caffeine cause significant synaptic enhancement under full blockade of A1 receptors by DPCPX $(P<0.01)$. This suggests that additional mechanisms other than blocking A1 receptors are involved in caffeine-induced enhancement. Then we adopted ryanodine, which blocks $\mathrm{Ca}^{2+}$ release from intracellular stores at high concentrations, to assess the involvement of ryanoine receptors in caffeine-induced synaptic potentiation in the presence of DPCPX. Preceding application of ryanodine $(100 \mu \mathrm{M})$ partially inhibited the caffeine-induced enhancement described above $(320 \pm 19 \%, \mathrm{n}=6$; Fig. $4 \mathrm{~A}$ and $\mathrm{B})$. The magnitude of caffeine-induced enhancement in DPCPX without ryanodine $(414 \pm 30 \%, \mathrm{n}=11$; open circles in Fig. 4B) is significantly different from those with ryanodine ( $P=0.047$; Fig. 4C). It should be noted that small transient increase in fEPSP amplitude was observed soon after application of ryanodine (shown by an arrowhead in Fig. 4B). This may reflect the property of ryanodine to lock ryanodine receptor channels to an open state at low concentrations and therefore elevate cytoplasmic $\mathrm{Ca}^{2+}$ levels within the presynaptic terminals (Ozawa, 2009).

Next we investigated presynaptic $\mathrm{Ca}^{2+}$ levels during caffeine-induced enhancement in the presence of DPCPX. DPCPX enhanced fEPSPs, but not affect basal fluorescence 
levels $(F)$ recorded from stratum lucidum in CA3 $(99 \pm 5 \%$ of control, $\mathrm{n}=5, P=0.55$; Fig. S1). Caffeine caused further enhancement of fEPSPs after application of DPCPX, and also enhanced $F$ value (to $117 \pm 3 \%$ of control, n $=5, P=0.0011$; Fig. S1). This suggests that caffeine induced $\mathrm{Ca}^{2+}$ release from presynaptic store via different mechanisms from blocking A1 receptors.

In the present study, we aimed to confirm presence and functional significance of presynaptic ryanodine receptors at the mossy fiber synapse. As in the previous study, application of adenosine A1 receptor agonist CPA suppressed mossy fiber transmission and subsequent application of A1 receptor antagonist DPCPX reversed and further enhanced than basal levels. This indicates that the mossy fiber terminals express presynaptic A1 receptors and adenosine in the extracellular space tonically suppresses transmission in our experimental conditions. The effect of blocking A1 receptors is expected to be sensitive to external condition that affects the dynamic state of ambient adenosine. Kukley et al. (2005) demonstrated that experimental conditions such as perfusion rate and composition of ACSF affect the DPCPX effects. Psarropoulou et al. (1990) found that the degree of caffeine-induced enhancement at CA1 synapse depends on the age of animals. It is also reported that the difference in temperature changed the rate of metabolism of extracellular adenine nucleotide and the ambient adenosine level (Dunwiddie and Masino, 2001). Nevertheless, the subsequent application of caffeine caused further enhancement of fEPSPs after treatment with DPCPX (Fig. 3D), and application of ryanodine decreased the enhancement by caffeine (Fig. 4B). These results indicate that caffeine certainly enhances mossy fiber synaptic transmission not only by blocking A1 receptors but also by, releasing $\mathrm{Ca}^{2+}$ from intracellular stores via ryanodine receptors. The relatively modest effect of ryanodine may presumably result from that stimulating action of caffeine overwhelmed the weaker blocking potency of ryanodine. 
In the fluorescence recording study, DPCPX didn't cause enhancement of $F$, although there is possibility that the effect of DPCPX was too small to detect in our recording system. However, it should be noted that subsequent application of caffeine caused significant increase in $\mathrm{Ca}^{2+}$ levels under full blockade of A1 receptors. Furthermore, previous study demonstrated that forskolin, which raise intracellular cyclic AMP levels and reportedly cause mossy fiber synaptic enhancement (Weisskopf et al., 1994), didn't affect $F$ value significantly (Kamiya et al., 2002). These results exclude the possibility that caffeine-induced presynaptic $\mathrm{Ca}^{2+}$ increase involves inhibiting effects of caffeine on $\mathrm{A} 1$ receptors and phosphodiesterase. Instead, $\mathrm{Ca}^{2+}$ release from presynaptic ryanodine-sensitive stores likely mediates the action of caffeine.

In summary, we pharmacologically demonstrated that caffeine-induced synaptic enhancement at the hippocampal mossy fiber synapses is mediated not only by adenosine A1 receptors but also by ryanodine receptors, at least in part. Strong immunostaining of type 2 ryanodine receptorts (RyR2) within mossy fibers as well as caffeine-induced increase in $\mathrm{Ca}^{2+}$ level within the presynaptic terminals (Shimizu et al., 2008) suggest that $\mathrm{Ca}^{2+}$ release through ryanodine receptors channels is involved in this synaptic enhancement. This strongly supports the notion that use-dependent amplification of presynaptic $\mathrm{Ca}^{2+}$ signaling by ryanodine receptors is a candidate mechanism for robust activity-dependency of mossy fiber transmission, which is crucial for "detonator" role of this particular synapse in hippocampal circuitry.

\section{Acknowledgements}

The authors are grateful to Dr. Takeshi Uchida for critical reading and useful advices on the manuscript. This work was supported by Grant-in-Aid for Scientific Research (B) (21300146 to H.K.) from Japan Society for the Promotion of Science. 


\section{References}

Dunwiddie, T.V., Hoffer, B.J., 1980. Adenine nucleotides and synaptic transmission in the in vitro rat hippocampus. Br. J. Pharmacol. 69, 59-68.

Dunwiddie, T.V., Masino, S.A., 2001. The role and regulation of adenosine in the central nervous system. Annu. Rev. Neurosci. 24, 31-55.

Erulkar, S.D., Rahamimoff, R., 1978. The role of calcium ions in tetanic and post-tetanic increase of miniature end-plate potential frequency. J. Physiol. 278, $501-511$.

Fredholm, B.B., Battig, K., Holmen, J., Nehlig, A., Zvartau, E.E., 1999. Actions of caffeine in the brain with special reference to factors that contribute to its widespread use. Pharmacol. Rev. 51, 83-133.

Geiger, J.R., Bischofberger, J., Vida, I., Frobe, U., Pfitzinger, S., Weber, H.J., Haverkampf, K., Jonas, P., 2002. Patch-clamp recording in brain slices with improved slicer technology. Pflugers. Arch. 443, 491-501.

Hagena, H., Manahan Vaughan, D., 2010. Frequency facilitation at mossy fiber-CA3 synapses of freely behaving rats contributes to the induction of persistent LTD via an adenosine-A1 receptor-regulated mechanism. Cereb. Cortex. 20, 1121-1130.

Kamiya, H., Shinozaki, H., Yamamoto, C., 1996. Activation of metabotropic glutamate receptor type 2/3 suppresses transmission at rat hippocampal mossy fibre synapses. J. Physiol. 493, 447-455.

Kamiya, H., Ozawa, S., 1999. Dual mechanism for presynaptic modulation by axonal metabotropic glutamate receptor at the mouse mossy fibre-CA3 synapse. J. Physiol. $518,497-506$

Kamiya, H., Umeda, K., Ozawa, S., Manabe, T., 2002. Presynaptic $\mathrm{Ca}^{2+}$ entry is 
unchanged during hippocampal mossy fiber long-term potentiation. J. Neurosci. 22, $10524-10528$

Klausnitzer, J., Manahan Vaughan, D., 2008. Frequency facilitation at mossy fiber-CA3 synapses of freely behaving rats is regulated by adenosine A1 receptors. J. Neurosci. $28,4836-4840$.

Kukley, M., Schwan, M., Fredholm, B.B., Dietrich, D., 2005. The role of extracellular adenosine in regulating mossy fiber synaptic plasticity. J. Neurosci. 25, 2832-2837.

Lauri, S.E., Bortolotto, Z.A., Nistico, R., Bleakman, D., Ornstein, P.L., Lodge, D., Isaac, J.T., Collingridge, G.L., 2003. A role for $\mathrm{Ca}^{2+}$ stores in kainate receptor-dependent synaptic facilitation and LTP at mossy fiber synapses in the hippocampus. Neuron. $39,327-341$.

Liang, Y., Yuan, L.L., Johnston, D., Gray, R., 2002. Calcium signaling at single mossy fiber presynaptic terminals in the rat hippocampus. J. Neurophysiol. 87, 1132-1137.

Lohse, M.J., Klotz, K.N., Lindenborn Fotinos, J., Reddington, M., Schwabe, U., Olsson, R.A., 1987. 8-Cyclopentyl-1,3-dipropylxanthine (DPCPX)--a selective high affinity antagonist radioligand for A1 adenosine receptors. Naunyn. Schmiedebergs. Arch. Pharmacol. 336, 204-210.

McPherson, T., Manek, R.V., Kolling, W., Long, S., Li, T., 2010. Physical Characterization of 1,3-dipropyl-8-cyclopentylxanthine (CPX). AAPS. PharmSciTech. 11, 720-728.

Moore, K.A., Nicoll, R.A., Schmitz, D., 2003. Adenosine gates synaptic plasticity at hippocampal mossy fiber synapses. Proc. Natl. Acad. Sci. U. S. A. 100, 14397-14402.

Nicoll, R.A., Schmitz, D., 2005. Synaptic plasticity at hippocampal mossy fibre synapses. Nat. Rev. Neurosci. 6, 863-876. 
Onodera, K., 1973. Effect of caffeine on the neuromuscular junction of the frog, and its relation to external calcium concentration. Jpn. J. Physiol. 23, 587-597.

Ozawa, T., 2010. Modulation of ryanodine receptor $\mathrm{Ca}^{2+}$ channels (Review). Mol Med Rep. 3, 199-204.

Psarropoulou, C., Kostopoulos, G., Haas, H.L., 1990. An electrophysiological study of the ontogenesis of adenosine receptors in the CA1 area of rat hippocampus. Brain. Res. Dev. Brain. Res. 55, 147-150.

Sato, I., Kamiya, H., 2009. Caffeine-induced synaptic enhancement under blockade of adenosine A1 receptors at the hippocampal mossy fiber synapse. Neurosci. Res. 65 (Suppl. 1), S143-S144

Sharma, G., Vijayaraghavan, S., 2003. Modulation of presynaptic store calcium induces release of glutamate and postsynaptic firing. Neuron. 38, 929-939.

Shimizu, H., Fukaya, M., Yamasaki, M., Watanabe, M., Manabe, T., Kamiya, H., 2008. Use-dependent amplification of presynaptic $\mathrm{Ca}^{2+}$ signaling by axonal ryanodine receptors at the hippocampal mossy fiber synapse. Proc. Natl. Acad. Sci. U. S. A. $105,11998-12003$.

Weisskopf, M.G., Castillo, P.E., Zalutsky, R.A., Nicoll, R.A., 1994. Mediation of hippocampal mossy fiber long-term potentiation by cyclic AMP. Science. 265, $1878-1882$ 


\section{Figure Legends}

Fig. 1. Effects of caffeine on synaptic transmission at the mossy fiber-CA3 synapse. (A) The representative traces recorded before and after application of $10 \mathrm{mM}$ caffeine. It should be noted that paired-pulse facilitation reduced during application of caffeine. (B) Time course of the amplitude of the first EPSPs. At the end of each experiment, $1 \mu \mathrm{M}$ DCG-IV was applied to confirm that the mossy fiber was selectively stimulated. Closed circles and error bars represent mean and SEM of multiple experiments, respectively. Six trials are included in each data point. The stimulus interval is set for 10 seconds.

Fig. 2. Effects of selective A1 receptor antagonist DPCPX. (A) The representative traces recorded during consecutive application of DPCPX at $1 \mu \mathrm{M}$ and $2 \mu \mathrm{M}$, respectively. (B) Time course of the first EPSPs. (C and D) Antagonism of adenosine A1 receptor-mediated synaptic inhibition by DPCPX. DPCPX (at $1 \mu \mathrm{M}$ ) completely reversed the inhibition of mossy fiber fEPSPs by $800 \mathrm{nM}$ CPA, a selective agonist of A1 receptors. Note that DPCPX further enhanced the fEPSPs than those before application of CPA and reached to the level almost identical with application of DPCPX alone.

Fig. 3. Interaction between the effects of caffeine and DPCPX on mossy fiber transmission. The representative traces (A) and time course (B) of the first EPSPs during application of $10 \mathrm{mM}$ caffeine and subsequent application of $1 \mu \mathrm{M}$ DPCPX. (C and D) Application of DPCPX was followed by caffeine treatment. 
Fig. 4. Effects of ryanodine on the amplitude of caffeine-induced enhancement in the presence of DPCPX. (A) The representative traces and time course of the first EPSPs during application of $1 \mu \mathrm{M}$ DPCPX, $100 \mu \mathrm{M}$ ryanodine, and $10 \mathrm{mM}$ caffeine. Data in Fig. 3D are shown by open circle for comparison. (C) Summary of the effects of caffeine in the presence of DPCPX with or without ryanodine (closed and open column, respectively). The difference was statistically significant $(* P<0.05)$.

Fig. S1. Caffeine-induced increase of presynaptic $\mathrm{Ca}^{2+}$ levels under blockade of $\mathrm{A} 1$ receptors by DPCPX. (A) Time course of the amplitudes of EPSPs during application of $1 \mu \mathrm{M}$ DPCPX and addition of $10 \mathrm{mM}$ caffeine. (B) Simultaneously recorded basal fluorescence levels $(F)$. Fluorescence was measured at $5 \mathrm{~min}$ intervals in order to avoid bleaching of fluorescence and phototoxity to neurons. 
Fig.1

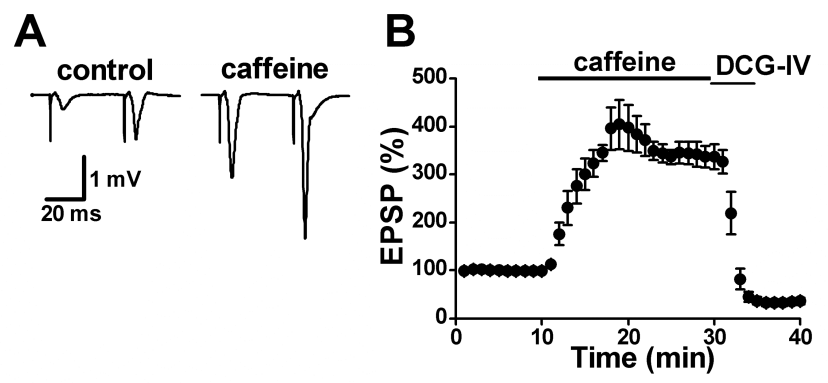

Fig.2

A

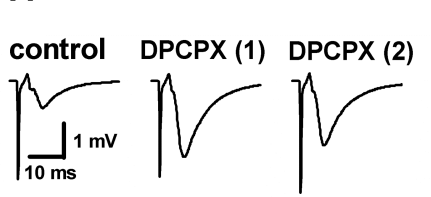

C

$\int_{\frac{J_{\mathrm{ms}}}{1 \mathrm{mv}}}^{\text {control }}$
B
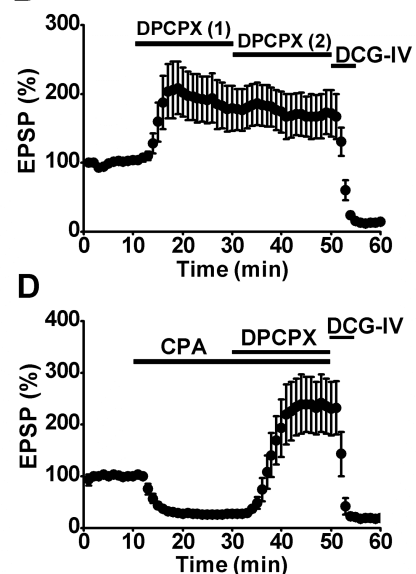
Fig.3

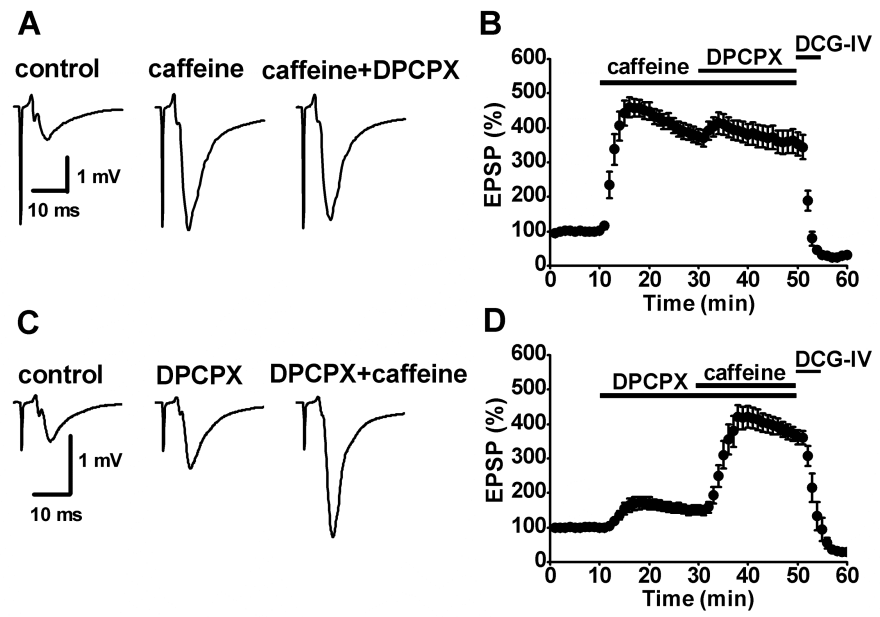

Fig.4

A

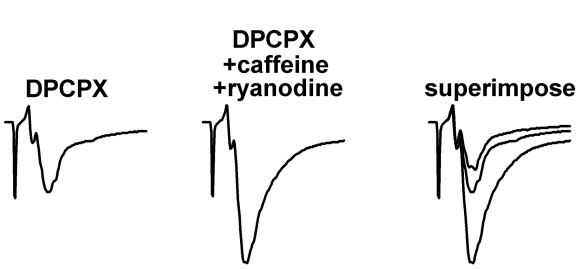

B

C

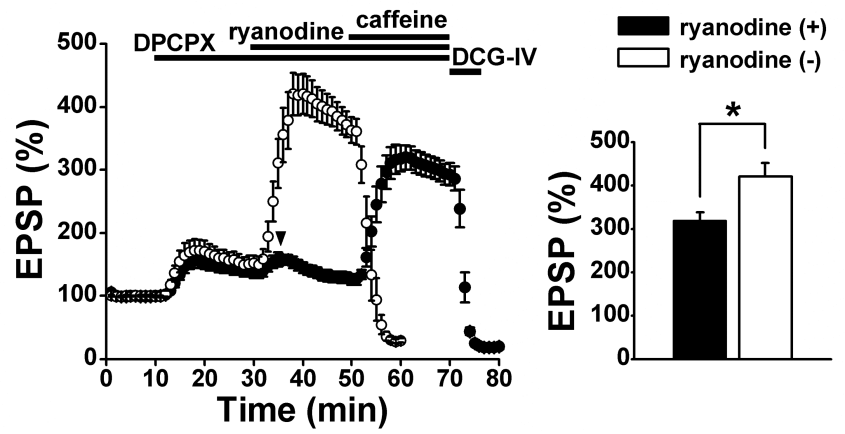


Fig.S1
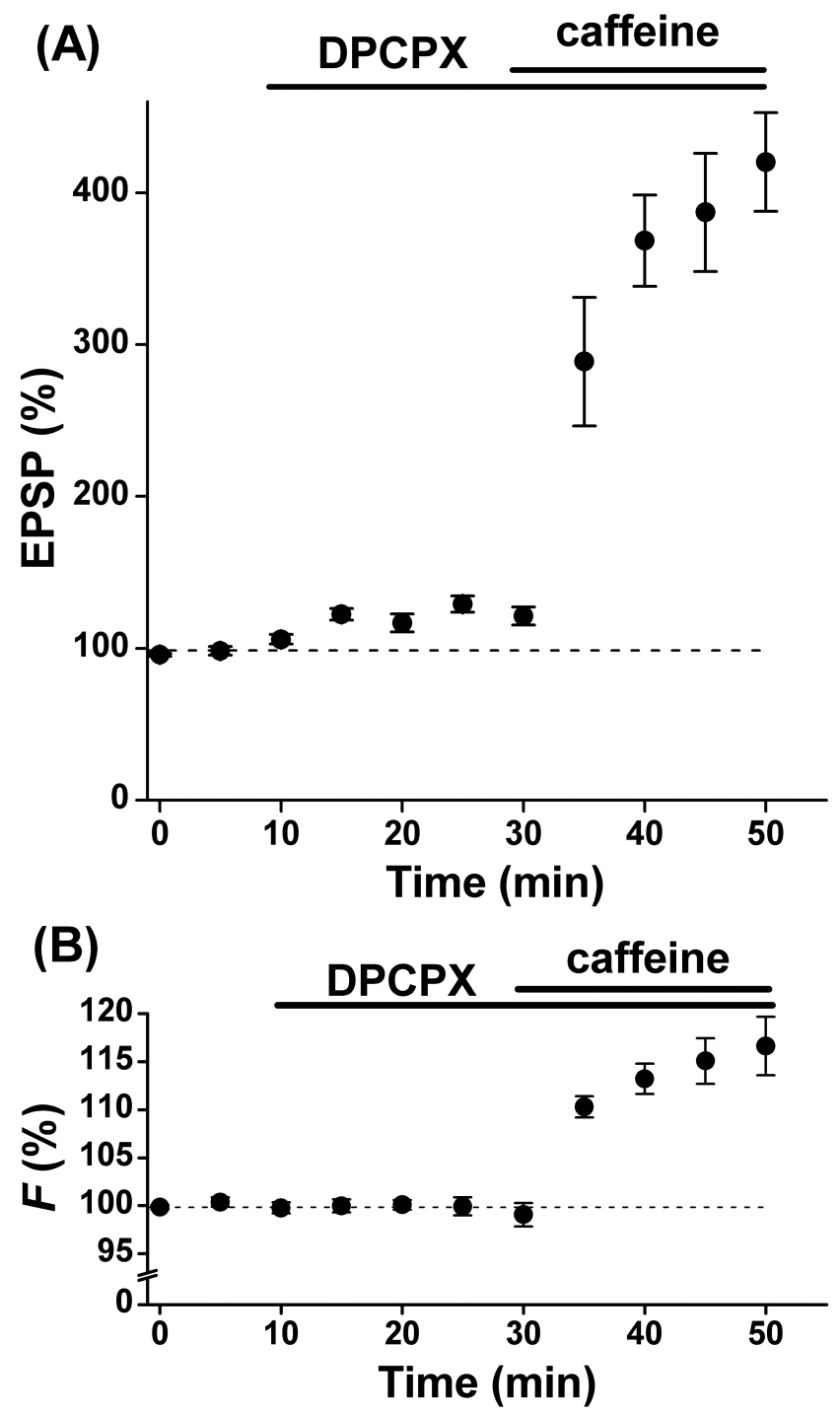